\title{
Research for waste water treatment technology with low production of excessive active sludge
}

\author{
Nikolay Makisha ${ }^{1, *}$ and Iana Panteleeva ${ }^{1}$ \\ ${ }^{1}$ Moscow state university of civil engineering, Yaroslavskoyeshosse, 26, Moscow, 129337, Russia
}

\begin{abstract}
The article reflects the possibility to create a technological scheme of waste water treatment of domestic and similar type of sewage within minimal amount of excessive active sludge by means of bioreactors with immobilized feed. There are various aspects to be considered: technical, economic, social and ecological. According to the above it is strongly needed to provide a combination of proper waste water treatment, minimal sludge formation and the possibility for a further use of the sludge. One of the ways to achieve the goal above is to use an immobilized feed in the aeration tank. The necessary experiments were carried out in the department of waste water treatment and water ecology. The article includes the scheme of the facility and other parameters of the experiments, which has been carried. The combination of aerobic and anaerobic processes helps to provide proper quality of integrated biological treatment. Chambers of the aeration reactor were also equipped with the polymer feed of various structures. The sludge treatment that was also strongly needed was made by means of aerobic stabilization with the use of ejecting aeration. The results of experiment showed a good effect in both components - sewage and sludge treatment. Afterwards there was also an industrial model launched which confirmed the results of the previous stage.
\end{abstract}

\section{Introduction}

The intensive growth of housing construction and the revival of industry caused systematic increase of emissions of all kinds of waste industrial, agricultural and domestic origin, capturing more and more vital space, causing irreparable damage to human health. An increase in infectious and oncologic diseases due to the decrease in the protective properties of the organism due to the fact that in adverse conditions suffers, first of all, the immune system. Further presence of people in the contaminated areas may result in disturbances in the reproductive sphere and the birth of physically and mentally defective offspring $[1,2]$.

As a result, we currently come close to the fact that irrational use of non-renewable natural resources and widespread pollution of the environment will lead to their complete exhaustion in the nearest future. The urgent measures have to be taken to restore the natural balance in the biosphere through the implementation of advanced technologies aimed at full

*Corresponding author: nmakisha@gmail.com 
utilization of various types of waste and restoration of the original properties of ecosystems [3-5].

The existing sewer system remains one of the main sources of pollution of water and land objects. The main hazard caused by discharge of untreated sewage or sewage that treatment does not meet the modern quality requirements.

Furthermore, sludge of wastewater treatment (in the forms of raw sludge and excessive)is a serious problem, which touches upon social and technical aspects.

The technical aspect appears due to the lack of reliable technologies that can help to:

a) minimize the generation of excessive active sludge and sediment;

b) provide a maximum recycle of sludge for the further use of its productsfor various needs.

Social and environmental aspect means catastrophic extension of the areas for storage of sludge, which leads to contamination of air, soil, surface and ground waters by pathogenic bacteria due to long-term and permanent accumulation and storage. It has a very adverse effect on the health of humans and animals and may lead to new epidemics and serious genetic changes [6-10].

In connection with the above circumstances, modern science faces many challenges in the field of water supply and sanitation, which mean new technologies development for treatment of household and similar to them by composition industrial wastewater, which would comply to the following conditions:

-quality of treated wastewater that meets modern standards (BOD, nitrogen and phosphorus compounds etc.).

-production a minimum amount of excessive sludge;

-use of the produced sludge as fertilizer or other means of facilitating its disposal;

-the compactness of treatment facilities and their area reduction.

\section{Waste water treatment technologies}

If modern requirements to the effluent quality are taken into account, a full sequence of wastewater treatment should include the following basic stages:

-equalizing of wastewater flow and concentrations;

-mechanical cleaning (screens, sand clarifiers, sedimentation tanks, etc.);

-deep anaerobic and aerobic treatment providing processes of nitrification and denitrification (aeration tanks, SBR reactors, biotanks, biofilters, etc.);

-phosphates removal by means of biological and chemical methods;

-multi-stage tertiary treatment (filters);

-disinfection treated wastewater.

Thus, application of the above meant purification technology means that formation of majority of wastes occurs at the stage of mechanical (raw sludge) and biological treatment (excessive active sludge)[11,12].

The amount of raw sludge may be reduce if primary sedimentation excluded from technological scheme. In this case, the unclarified wastewater treated from sand and large mechanical impurities directly goes to biological purification. This technique is widely spread now, especially if biogenic elements have to be removed $[2,6,13]$. However, that may cause a slight growth of excessive activated sludge[14,15].In this case, application of immobilized microorganisms can help to avoid additional growth of excessive sludge. On the other hand, unclarified sewage frequently may cause bulking of fixed or floating bed installed in biological treatment tank.

As a result, the following treatment scheme can be as follow:

-flow equalization;

-sand and coarse dirt removal (screens and sand clarifiers); 
-primary sedimentation (settling tanks with thin-layer elements);

-biological treatment in reactors with attached microflora;

-tertiary treatment;

The sludge production only occurs during primary settling. For the treatment of this sludge to reduce its volume, stabilize and improve the sedimentation and vodoohda properties requires intensification of treatment facilities precipitation [16-17].

\section{How to reduce amount of sludge at wastewater treatment plants}

Modern methods of biological treatment are based on the activity of the active sludge or biofilm, i.e. naturall biological community, which is formed in each case depending on the wastewater composition and the selected treatment mode. The formation of the biocenose is a long process that goes constantly during wastewater treatment in industrial facilities: aeration tanks or biofilters [18-21]. Environmental biotechnologies using immobilized microflora (with the formation of biological communities on the fixed or floating bed) gain at present wider application [6,12].Immobilization of microbial cells stimulates complex multistage processes, providesa better protection of the cells against negative exposure and ensures high concentration of cells in the biological reactor [13, 22-24].

The idea to integrate the positive properties of biological filters(high oxidative and mass transfer properties of its microorganisms, vitality and low energy consumption for oxidation of pollutants of wastewater) and aeration basins (high treatment efficiency of wastewater, the possibility of deep mineralization of excess sludge and the possibility of creating a high concentration of sludge in the reaction volume) is the key point for the biological treatment facilities with attached sludge.

The use of immobilized micro flora secures 5 to 7 time lower production of excess activated sludge in comparison with the formation of active sludge in the aeration tank. Table 1 show positive results of the application of immobilized activated sludge that allows increasing the dose of sludge in the aeration facility, which accordingly improves their oxidative capacity and creates favorable conditions for development and retention of specific slow-growing strains of microorganisms able to destruct various hardly oxidized contaminants [25-27].

Table 1. Application of immobilized active sludge.

\begin{tabular}{|l|l|}
\hline \multicolumn{1}{|c|}{ Test description } & \multicolumn{1}{c|}{ Result } \\
\hline $\begin{array}{l}\text { Comparison of the laboratory } \\
\text { models of the biological treatment } \\
\text { plants and without with a fixed } \\
\text { bed having an equal load of } \\
\text { styrene-wastewater }\end{array}$ & $\begin{array}{l}\text { Immobilization of corrugated and perforated PVC plates } \\
\text { helps to increase the oxidative capacity of 4.4-9.6 times } \\
\text { (form 1.85 to 8.1-17.8 g/l per day) }\end{array}$ \\
\hline $\begin{array}{l}\text { Use of bundles of nylon fibers for } \\
\text { adhesion of microorganisms }\end{array}$ & $\begin{array}{l}\text { - Sludge concentration in laboratory model of aeration } \\
\text { tank grew from 0.3 to 3.0 g/l } \\
\text { - HRT dropped from 36 to 6 hours with initial and } \\
\text { discharge values of phenol concentrations } 660 \text { and } 10 \\
\text { mg/l correspondingly. }\end{array}$ \\
\hline $\begin{array}{l}\text { Test in pilot mode of metal grid as as } \\
\text { a carrier of the microorganisms }\end{array}$ & $\begin{array}{l}\text { - Sludge concentration in pilot model of aeration tank } \\
\text { grew from 0.3 to 1.2-1.5 g/l; } \\
\text { - HRT dropped from 36 to 10-8 hours with initial and } \\
\text { discharge values of phenol concentrations } 600 \text { and } 20 \\
\text { mg/l correspondingly }\end{array}$ \\
\hline $\begin{array}{l}\text { Comparative study of } \\
\text { decomposition of hydrocarbons by }\end{array}$ & $\begin{array}{l}\text { Cultivation time of active sludge - 20 hours. } \\
\text { Media - concentration of petrochemicals is } 907 \mathrm{mg} / 1 .\end{array}$ \\
\hline
\end{tabular}




\begin{tabular}{|l|l|}
\hline $\begin{array}{l}\text { means of floating and } \\
\text { immobilized on different bed } \\
\text { (glass fibre, nylon wire brushes, } \\
\text { nylon cord) }\end{array}$ & $\begin{array}{l}\text { Effect of contaminant degradation: } \\
\text { Immobilized sludge }-89.6 \% \\
\text { Floating sludge }-25 \%\end{array}$ \\
\hline $\begin{array}{l}\text { Consolidation of sludge on the } \\
\text { fibrous carrier }\end{array}$ & $\begin{array}{l}\text { Acceleration of specific biocenose formation and } \\
\text { reduction of petrochemicals concentration in treated } \\
\text { water from 711 to 35 mg/l }\end{array}$ \\
\hline
\end{tabular}

A scope of inert carriers for the immobilization of microflora of sewage treatment plants is quite wide: sand, haydite, crushed stone, gravel, ash, coal, diatomite earth, glass beads, fiberglass, glass fiber, basalt fiber, ceramics, metal mesh, Raschig rings, and other media that provides increased surface area. The materials may have density equal to or less than the density of the treated water (polyurethane foam, foamed plastic, porous glass, cox and others); these materials are floated by air or gas.

There are various carriers known that are made in the form of plates with a mesh structure of various natural and synthetic materials, fibers of nylon, polyester, polyvinyl chloride, nylon cord and polyurethane, as well as materials that involve the immobilization by inclusion of cells in polymers (agar, carrageenan, alginate, polyurethane foam, polyacrylamide, cellulose gels).

\section{Solutions for facilities biological treatment of waste water with low production of excessive sludge}

Biological treatment facilities with minimal formation of excess sludge operate on the principle biotank (bioreactor) - aeration tank with a fixed bed, made in the form of cassettes or blocks of rigid elements or flexible roll materials. Fixed bed allows increasing the sludge concentration in the bioreactor due to the aggregation of microorganisms on it. Increase of the sludge concentration results in growth of capacity of treatment facility. However, the capacity growth is limited in normal conditions by the operation of secondary sedimentation tanks are not able to separate the sludge mixture at a concentration exceeding 4-6 $\mathrm{g} / 1[1,2,28]$. There is periodic regeneration from the excessive accumulation of biomass required by intensive aeration if bulk and fibrous materials used as a fixed bed.

The bioreactor is divided into sections, each of which is filled with feed of a certain type. The aeration basins work as the ideal mixing reactors: waste water successively passes through all sections of the reactor, contacting with immobilized biocenose. The design of the basin eliminates the leakage of untreated wastewater and provides high quality of wastewater treatment[11,12,17,29]. Implemented general organization of the wastewater treatment process makes system the system working in the mode of extended aeration, designed for the complete oxidation of organic pollutants of wastewater, the mineralization of the biomass and nitrification. Aerobic and anaerobic zones are separated to ensure the nitrification and denitrification processes; the system also need a recirculation of effluents containing nitrates and nitrites[30-31].

The oxidation of organic pollutants wastewater is made by immobilized microflora. The operation conditions of the bioreactor with minimization of excess sludge are specific and different from the conditions in which work the existing wastewater treatment bioreactors. Fixed bed is located to increase the specific surface area, and through the entire volume of the bioreactor. As a result there is no floating sludge inside the tank.

Meanwhile, incompletely oxidized organic contaminants as well as biofilm taken out of the previous chambers of the bioreactor are the food for microorganisms in subsequent stages of treatment. This is the way to achieve minimization of excessive biomass and prevent the sedimentation load. 
A new type of rigid planar of fixed bed may be applied to increase the contact surface for the waste water treatment facilities of small capacity. Fixed bedis made of fibrous mats with thickness up to $50 \mathrm{~mm}$, with different distance between the fibers. The type of bed improves the mass immobilized on the surface of the material and helps to avoided siltation. The increase of the biomass layer stimulates the development of nitrifying and denitrifying microorganisms. The mats of in-plane load have to be located vertically and parallel to the fluid flow direction to optimize the hydrodynamic mode of liquid sewage motion and to form integrated biological mass. Aeration of sewage and the possible regeneration of the bed under the mats is performed by the membrane aerators installed in the tank.

Traditional technological scheme of wastewater treatment facilities require secondary settling tanks[7,15,32] designed to accomplish the separation of sludge from purified water. However, the technology described above assumes zero amount of floating sludge consequently secondary clarifiers can be waived. This circumstance allows to reduce area occupied by treatment facilities and to simplify their operation.

\section{Experimental research}

There was an experimental research conducted based on the above data to study the process of biological wastewater treatment with the minimization of excessive sludge. The waste water had the following concentrations of contaminants

-Suspended solids - 49-80 mg/l;

- $\mathrm{BOD}_{5}-75-190 \mathrm{mg} / \mathrm{l}$;

$-\mathrm{N}-\mathrm{NH}_{4}-27.9-61.52 \mathrm{mg} / \mathrm{l}$.

Thefacilityhad4chamberequippedwithabovementionedfixedbedandentirevolumeof $\quad 46.1$ hydraulic retention time was from 20 to 24 hours. The laboratory model was under operation for 5 months providing the following effluent concentrations of pollutants:

- Suspended solids $-<2 \mathrm{mg} / \mathrm{l}$;

- $\mathrm{BOD}_{5}-1-6 \mathrm{mg} / \mathrm{l}$

- $\mathrm{N}-\mathrm{NH}_{4}-1.9-3.9 \mathrm{mg} / \mathrm{l}$.

The concentration of suspended solids through the entire research was under $2 \mathrm{mg} / \mathrm{l}$ and there was no evidence of bed clogging. Both these fact speak in favour of minimal excessive sludge production.

\section{References}

1. N. Makisha, V. Scherbakov, A. Smirnov, E. Scherbina, IJAER10, 44347-44349 (2015)

2. V. Scherbakov, E. Gogina, T. Schukina, N. Kuznetsova, N. Makisha, E. Poupyrev, IJAER10, 44353-44356 (2015)

3. E. Gogina, I. Gulshin, Pr. Eng.117, 107-113 (2015)

4. A.G. Pervov, A.P. Andrianov, T.P. Gorbunova, A.S. Bagdasaryan, Petr. Chem.55 (10), 879-886 (2015)

5. I. Gulshin, A. Kuzina, IJAER10, 42618-42623 (2015)

6. E.S. Gogina, O.V. Yantsen, O.A. Ruzhitskaya, AMM 580-583, 2354-2357 (2014)

7. O.A. Ruzhitskaya, E.S. Gogina, AMR919-921, 2141-2144 (2014)

8. A. Volkov, V. Chulkov, R. Kazaryan, M. Fachratov, O. Kyzina, R. Gazaryan, AMM580-583, 2281-2284, (2014)

9. N. Makisha, E. Gogina, AMM361-363, 632-635 (2013) 
10. A.G. Pervov, A.P. Andrianov, E.B. Yurchevskiy, Petr. Chem.55 (10), 871-878 (2015)

11. O.A. Ruzhitskaya, E.S. Gogina, AMR919-921, 2153-2156 (2014)

12. E. Gogina, N. Makisha, AMM587-589, 636-639 (2014)

13. E. Gogina, A. Pelipenko, MATECCONF73, 03007 (2016)

14. V.N. Varapaev, S.A. Doroshenko, A.Y. Trotsko, A.V.Doroshenko, IJAER10, 4258842592 (2015)

15. N. Makisha, O. Yantsen, AMM587-589,640-643 (2014)

16. O. Kuzina, E. Pankratov, V. Tkachev, MATECCONF 86, 05023 (2016)

17. N. Makisha, E. Gogina, AMM 587-589, 644-647 (2014)

18. V. Orlov, A. Andrianov, AMM580-583, 2398-2402 (2014)

19. N. Makisha, Y. Voronov, E. Poupyrev, V. Volshanik, IJAER10, 41919-41922 (2015)

20. V.N. Varapaev, A.V. Doroshenko, I.Y. Lantsova, Pr. Eng.153, 816-823 (2016)

21. N. Zaletova, Y. Voronov, N. Makisha, IJAER10, 42454-42455 (2015)

22. N. Makisha, E. Gogina, AMM361-363, 628-631 (2013)

23. E.S. Gogina, O.A. Ruzhitskaya, O.V. Yantsen. AMR919-921, 2145-2148 (2014)

24. N. Makisha, E3sconf6, 01002 (2016)

25. A.G. Pervov, A.P. Andrianov, DWT35 (1-3), $2-9$ (2011)

26. E. Gogina, I. Gulshin, AMM580-583, 2367-2369 (2014)

27. A. Volkov, O. Kuzina, Pr. Eng.153, 838-843 (2016)

28. N. Makisha, Pr. Eng.165, 1087-1091 (2016)

29. A.A. Volkov, A.V. Sedov, P.D. Chelyshkov, D.A. Lysenko, A.V. Doroshenko, IJAER10, 43269-43272 (2015)

30. N. Makisha, Pr. Eng.165, 1092-1097 (2016)

31. E. Gogina, I. Gulshin, Pr. Eng.153, 189-194 (2016)

32. A.G. Pervov, A.P. Andrianov, V.A. Chukhin, R.V. Efremov, IJAER10, 43517-43525 (2015) 